\title{
The effect of concentration and silica surface modification on the poly(butyl acrylate-co-methyl methacrylate) properties
}

\author{
Zrinka Buhin Sturlić and Mirela Leskovac \\ Department of Surface Engineering of Polymer Materials, Faculty of Chemical Engineering and Technology, \\ University of Zagreb, Zagreb, Croatia \\ Krunoslav Žižek \\ Department of Mechanical and Thermal Process Engineering, Faculty of Chemical Engineering and Technology, \\ University of Zagreb, Zagreb, Croatia, and \\ Sanja Lučić Blagojević \\ Department of Surface Engineering of Polymer Materials, Faculty of Chemical Engineering and Technology, \\ University of Zagreb, Zagreb, Croatia
}

\begin{abstract}
Purpose - The purpose of this paper is to prepare stabile emulsions with $0-15 \%$ of colloidal silica and high monomer/water ratio and to investigate the influence of silica addition and surface modification on the polyacrylate properties.

Design/methodology/approach - Improving the properties of the composite can be achieved by optimizing the compatibility between the phases of the composite system with improving the interactions at the matrix/filler interface. Therefore, the silica surface was modified with nonionic emulsifier octylphenol ethoxylate, cationic initiator 2,2'-azobis-(amidinopropane dihydrochloride) and 3-methacryloxypropyltrimethoxysilane and polyacrylate/silica nanocomposites were prepared via in situ emulsion polymerization. Particle size distribution, rheological properties of the emulsions and morphology, thermal properties and mechanical properties of the film prepared from the emulsions were investigated.

Findings - Polyacrylate/silica systems with unmodified silica, silica modified with nonionic emulsifier and cationic initiator have micrometer, while pure PA matrix and systems with silica modified with silane have nanometer particle sizes. Addition and surface modification of the filler increased emulsion viscosity. Agglomeration of silica particles in composites was reduced with silica surface modification. Silica filler improves thermal stability and tensile strength of polyacrylate.

Originality/value - This paper provides broad spectrum of information depending on filler surface modification and latex preparation via in situ emulsion polymerization and properties with high amount of filler and monomer/water ratio with the aim that prepared latex is suitable for film formation and final application.
\end{abstract}

Keywords Emulsions, Nanocomposite, Silica, Polyacrylate

Paper type Research paper

\section{Introduction}

Properties of the polymer matrix and the shape and size, specific surface area, packing, surface activity and distribution of the filler in matrix, as well as interactions of the filler with polymer matrix have significant effect on the composite properties. The strength of interactions can be modified by filler pretreatment with different surface modifiers. The $\mathrm{pH}$, modifier amount, time of the reaction and water amounts have influence on the surface modification of the nanoparticles (Ajayan et al., 2003; Lotfy et al., 2018). Nanocomposites can be prepared by mixing of the filler and polymer matrix or by in situ

The current issue and full text archive of this journal is available on Emerald Insight at: https://www.emerald.com/insight/0369-9420.htm

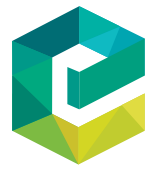

Pigment \& Resin Technology

51/2 (2022) 253-263

Emerald Publishing Limited [ISSN 0369-9420]

[DOI 10.1108/PRT-01-2021-0006] polymerization. Better dispersion and distribution of the filler in polymer matrix can be achieved by in situ polymerization (Hashemi-Nasaba and Mirabedini, 2013; Kazakova et al., 2018; Motaung et al., 2017).

For the application of suspensions and emulsions in products such as paints, cement, color printing, liquid adhesives, sealants, cleaning products and food rheological properties are very important. As the polyacrylate emulsions (PA) could be

\footnotetext{
(C) Zrinka Buhin Šturlić, Mirela Leskovac, Krunoslav Žižek and Sanja Lučić Blagojević. Published by Emerald Publishing Limited. This article is published under the Creative Commons Attribution (CC BY 4.0) licence. Anyone may reproduce, distribute, translate and create derivative works of this article (for both commercial and non-commercial purposes), subject to full attribution to the original publication and authors. The full terms of this licence may be seen at http://creativecommons.org/licences/by/ 4.0/legalcode
}

Received 23 January 2021

Revised 23 March 2021

Accepted 1 April 2021 
used as coatings, it is very important that such emulsions have good rheological properties, such as to flow evenly over the surface (Anderson and Daniels, 2003). At low shear rates, the latex emulsion has high viscosity $\sim 10000 \mathrm{mPa}$ s, and at high shear rates their viscosity is lower than $100 \mathrm{mPa}$ s. The viscosity of the latex can be increased with the addition of water-soluble viscosity modifier, of fumed and colloidal silica [...] (Platikanov and Exerowa, 2009). Particle size distribution, interactions between the particles and the concentration of solid particles have significant effect on the latex viscosity. At high concentration of solid particles viscosity increases rapidly. At the same concentration of solid particles, the viscosity can be increased or decreased depending upon the particle size distribution (Schneider et al., 2002). Rheological behavior of the fluids is usually described using rheological models. The viscosity of Newtonian fluids is calculated from the equation (1).

$$
\tau=\gamma \cdot \eta
$$

Pseudoplastic behavior can be described with Ostwald-de Waele model equation (2); where $\tau$ is shear stress, $\gamma$ is shear rate, $k$ is the flow consistency index and $n$ is flow behavior index.

$$
\tau=k \cdot \gamma^{n}
$$

Amorphous silica (pyrogenic and colloidal) is often used as an inorganic component (filler) in polymeric materials due to its chemical stability, large specific surface area and easy availability (Li et al., 2020; Najam et al., 2020; Ma et al., 2021). If the silica particles are uniformly distributed and dispersed in the polymer matrix, an improvement in the mechanical strength, stiffness, impact toughness and optical properties of the composite materials can be achieved. Improving the properties of the composite can be achieved by optimizing the compatibility between the phases of the composite system, by bonding the filler and the polymer matrix by covalent bonds or by changing the physical nature of the filler surface and thus improve the interactions at the matrix/filler interface (Laoutid et al., 2009; Liua et al., 2003; Rong et al., 2006). The chemical bond between the polymer and the filler can be achieved by grafting organic or inorganic reactive groups, for example silane to the surface of the inorganic particle. Borguet-Lami et al. (Bourgeat-Lami et al., 2006) modified silica surface with $\gamma$-methacryloxypropyltrimethoxysilane (MPS) to achieve formation, of a nanocomposite particle consist of a silica particle surround by polymer (polystyrene), by in situ emulsion polymerization. The aim of the work was to explain the influence of MPS grafting density, silica size and concentration on the polymerization kinetics and nanocomposite particle morphology. Depending upon above mentioned factors different nanocomposite morphology was obtained. Cationic initiator, 2,2'-azobis-(amidinopropane dihydrochloride) (AIBA) is often use to modified filler surface to achieve electrostatic interactions between the silica and polymer surface. Luna-Xavier et al. (Luna-Xavier et al., 2001) and Qi et al. (Qi et al., 2006) where able to synthesize nanocomposite particles with the core-shell structure with the use of AIBA. Dashtizadeh et al. (Dashtizadeh et al., 2011) treated nanosilica particles with surfactants, to prepare acrylic emulsion with improved properties of solvent resistance and surfaces hardness.

The aim of this study was to investigate the effect of colloidal silica filler concentration and silica surface modification with nonionic emulsifier, cationic initiator and silane on the emulsion particle size distribution (PSD) and rheology. Polyacrylate + silica emulsions were prepared by in situ emulsion polymerization. From the obtained emulsions films were prepared by drying and their morphology, thermal and mechanical properties were investigated. The significant difference between the mentioned studies (Bourgeat-Lami et al., 2006; Luna-Xavier et al., 2001; Qi et al., 2006; Dashtizadeh et al., 2011), and this work is the monomer/water ratio. The monomer/water weight ratio in the systems from the literature was from $1 / 100$ to $20 / 100$ and in the systems prepared in this work monomer/water ratio was significantly higher; 70/100 with the aim that prepared latex is suitable for final application and film formation. Due to the high monomer/ water ratio, high nanosilica concentration (15 Wt.\%) and surface modification it was very difficult to optimize the in situ emulsion polymerization process to obtain stable $\mathrm{PA}+$ silica emulsion and homogeneous film.

\section{Experimental}

\subsection{Materials}

Monomers methyl methacrylate (MMA), butyl acrylate (BA) and initiators, ammonium persulfate (APS) and cationic initiator 2,2'-azobis(2-amidinopropane) dihydrochloride (AIBA) from Acros Organics, were used for emulsion polymerization. Two types of emulsifiers were used, anionic emulsifier sodium lauryl sulphate ether DISPONIL FES 77, supplied from COGNIS, Germany, and nonionic emulsifier (NE) octylphenol ethoxylate Triton TX-100. Colloidal silica, i.e. silica aqueous dispersion (30 mass.\%) with the trade name KLEBOSOL 30R25 was kindly supplied by AZ Electronic Materials, France. Particle size of colloidal silica particles is $25 \mathrm{~nm}$. For silica surface modification 3methacryloxypropyltrimethoxysilane (MPS) supplied from ABCR GmbH was used.

\subsection{Polymerization procedure}

Polyacrylate emulsion was synthesized by emulsion polymerization and PA+silica systems by in situ emulsion polymerization in the concentration range $0-15 \mathrm{Wt} . \%$ of silica according to the monomer mass. To prepare PA+ silica systems with modified silica surface, prior to polymerization, modification of silica surface was performed. In the present processes, the total monomer weight was $65.52 \mathrm{~g}, \mathrm{BA} / \mathrm{MMA} 1 /$ 1 , the monomer/water ratio was $70 / 100$, and the total amount of anionic emulsifier Disponil FES 77 was $20.0 \mathrm{~g}$. The exact amounts of components used in in situ emulsion polymerization of PA+ silica systems are presented in Table 1 .

2.2.1 Emulsion polymerization of neat poly (BA-co-MMA) and in situ emulsion polymerization of $P A+$ silica systems with unmodified silica

Pre-emulsion consisting of the total amount of anionic emulsifier, monomer, initiator, and $52 \%$ of water was prepared. The reactor is then filled with water (for neat PA emulsion 
Table 1 Mass of components for in situ emulsion polymerization

\begin{tabular}{|c|c|c|c|c|c|}
\hline \multicolumn{6}{|c|}{ Silica amount in PA+silica emulsions } \\
\hline Components (g) & $0 \%$ & $1 \%$ & $5 \%$ & $10 \%$ & $15 \%$ \\
\hline Water & 93.8 & 93.80 & 93.80 & 93.80 & 93.80 \\
\hline Monomers & 65.52 & 65.52 & 65.52 & 65.52 & 65.52 \\
\hline Anionic emulsifier (Disponil FES 77) & 20.00 & 20.00 & 20.00 & 20.00 & 20.00 \\
\hline Initiator APS & 0.41 & 0.41 & 0.41 & 0.41 & 0.41 \\
\hline $30 \% \mathrm{SiO}_{2}$ dispersion & - & 2.18 & 10.92 & 21.84 & 32.76 \\
\hline Nonionic emulsifier (NE) & - & 0.019 & 0.097 & 0.194 & 0.290 \\
\hline Cationic initiator (AIBA) & - & 0.002 & 0.012 & 0.023 & 0.035 \\
\hline Silane (MPS) & - & 0.010 & 0.021 & 0.042 & 0.063 \\
\hline
\end{tabular}

polymerization) or with unmodified silica dispersed in water, and heated to a temperature $82-85^{\circ} \mathrm{C}$. Once a temperature was $>82^{\circ} \mathrm{C}$ pre-emulsion was added dropwise to the reactor. When all pre-emulsion was added in the reactor, small amount of the APS solution was added to complete the polymerization.

\subsubsection{Silica surface modification}

2.2.2.1 Adsorption of nonionic emulsifier. Dispersion of silica in water was treated in ultrasonic bath and then placed in the reactor. The dispersion was heated to a temperature $70^{\circ} \mathrm{C}$ and nonionic emulsifier was added. The adsorption of nonionic emulsifier was performed for $15 \mathrm{~min}$.

2.2.2.2 Adsorption of cationic initiator 2,2'-azobis-(amidinopropane dihydrochloride. Dispersion of silica in water was treated in ultrasonic bath. Certain amount of cationic initiator AIBA was added to the silica dispersion dropwise at room temperature, and $\mathrm{pH}$ solution was adjusted to $\sim 10$ with $\mathrm{NH}_{4} \mathrm{OH}$. The adsorption of cationic initiator was performed for $15 \mathrm{~min}$.

2.2.2.3 Silica surface modification with silane. Dispersion of silica in water was treated in ultrasonic bath. Small amount of anionic emulsifier is added and then silane, MPS, dropwise at room temperature. $\mathrm{pH}$ of dispersion was adjusted to 9.5 with $\mathrm{NH}_{4} \mathrm{OH}$ solution. Dispersion is then stirred at room temperature for $17 \mathrm{~h}$, placed into the reactor, heated at $70^{\circ} \mathrm{C}$ to promote covalent bonding of silane to silica surface ( $15 \mathrm{~min}$ ). Anionic emulsifier is added in before heating to prevent coalescence of silica particles due to the silane addition.

\subsubsection{In situ emulsion polymerization of $P A+$ silica systems with modified silica}

After adsorption of nonionic emulsifier, AIBA or silane on silica surface small amount of initiator APS and monomer were added to initiate the "seed" phase of emulsion polymerization. In systems where silica is modified with nonionic emulsifier and silane, the reactor content was heated at $82-85^{\circ} \mathrm{C}$ and polymerization was carried out for $1 \mathrm{~h}$. After the "seed" phase $1.44 \mathrm{~g}$ of an anionic emulsifier was added to stabilize the arisen organic/inorganic particles. Pre-emulsion was then added dropwise, followed by the addition of a small amount of APS to finish the polymerization. In systems where silica is modified with cationic initiator, AIBA, the emulsion polymerization was conducted at temperature $\sim 70^{\circ} \mathrm{C}$ since at this temperature decomposition of AIBA is the fastest. Also, in the dispersion of silica and AIBA in the "seed" phase, the nonionic emulsifier was added instead of anionic emulsifier SDS. Function of nonionic emulsifier, here, is to stabilize growing organic/inorganic particles in "seed" phase of emulsion polymerization.

In systems where silica is modified with silane (MPS), it was not possible to prepare PA+K25 systems with 10 and $15 \%$ of silica. At higher silica concentration higher amount of silane need to be added to achieve efficient modification of silica surface and the sol evolves towards gel formation. Besides, silane molecules attached on silica can also interact mutually. These reasons could be a cause of emulsions coagulation with higher amount of silica modified with silane (Table 1). With the described procedure, stable PA+K25 systems with 1 and 5\% with silica modified with silane were prepared.

\subsection{Film preparation}

$\mathrm{PA}$ and PA+ silica films were prepared by applying an emulsion on a glass substrate with an applicator $(40 \mu \mathrm{m})$. To improve the film formation, the samples were dried in an oven for $24 \mathrm{~h}$ at $65^{\circ} \mathrm{C}$.

\subsection{Characterization}

Particle size distribution (PSD) for PA+silica emulsions was successfully determined in wet mode using the laser diffraction method (SALD 3101, Shimadzu) with refraction index of 0-1.95. Prior to particle size analysis, emulsions were homogenized on a magnetic stirrer for 10 minutes at $200 \mathrm{rpm}$. Rheological properties of emulsions were measured using rotational rheometer Brookfield DV III + with constant increasing of shear rate from 0 to $182 \mathrm{~s}^{-1}$, and then with constant decreasing of shear rate from 182 to $0 \mathrm{~s}^{-1}$, at $25^{\circ} \mathrm{C}$. Morphology of the PA+ silica systems was investigated using scanning electron microscope (SEM) VEGA 3 SBH Easy Probe (Tescan). The samples for SEM where prepared from emulsions diluted 200 times to avoid eventual particles coalescence and film formation. Glass transition temperatures of the films $(\sim 10 \mathrm{mg})$ were determined using differential scanning calorimetry, on the instrument DSC $823^{\mathrm{e}}$ (Mettler Toledo) in two heating cycles in temperature range -40 to $50^{\circ} \mathrm{C}$ with heating/ cooling rate $10^{\circ} \mathrm{C} \min ^{-1}$ in $\mathrm{N}_{2}\left(50 \mathrm{ml} \mathrm{min}^{-1}\right)$. Thermal stability of the PA and PA+silica films was determined with thermogravimetric analysis (TGA) on Q500measuring unit (TA Instruments). Each sample with a mass of $\sim 10 \mathrm{mg}$ was heated in the air from ambient temperature to $500^{\circ} \mathrm{C}$ with a heating rate of $10^{\circ} \mathrm{C} \mathrm{min}^{-1}$. Mechanical properties of the films were determined with tensile test on Universal testing machine Zwick 1445 at $25^{\circ} \mathrm{C}$ and $\mathrm{Rh}=50 \%$ with test speed $100 \mathrm{~mm} \mathrm{~min}^{-1}$ on 10 specimens for each sample tested. 


\section{Results and discussion}

\subsection{Particle size distribution}

Particle size distributions (PSDs) of PA+ silica emulsions are shown on Figure 1. Averaged PSD is expressed on the basis of volume, with diameter mean, $d_{3,2}$. Neat PA emulsion is of nanometer particle size range, all PA particles are smaller than $80 \mathrm{~nm}$ and with the instrument SALD, 3101 it was not possible to obtain repeatable particle size distribution curve. In comparison to neat PA emulsion, the emulsions with unmodified colloidal silica filler and silica modified with nonionic emulsifier and cationic initiator, in entire concentration range $(0-15 \%)$ are in micrometer ranges.

All systems prepared with unmodified silica (PA+K25) [Figure 1(a)] exhibited bimodal particle size distribution. Specific behavior is observed for system PA+K25 1\% where particle size distribution is bimodal with particles in nanometer and in micrometer range. A possible explanation for such occurrence might be that in this system two kinds of particles are formed, nanometer neat PA particles and micrometer $\mathrm{PA}+$ silica particles. According to previous findings [LunaXavier et al., 2001 in systems with untreated silica filler encapsulation of silica particles with polymer is possible if potassium persulfate, KPS is used as the initiator. Since ammonium persulfate (APS) used in this paper is also a persulfate initiator it can be assumed that it will react with the same mechanism as the KPS. Also, composite particles can be formed just by "lay on" of polymer particles on unmodified filler surface (Bourgeat-Lami et al., 2006). Therefore, in the system there are neat polyacrylate particles with nanometer particle sizes and larger PA/silica composite particles. For $\mathrm{PA}+$ silica systems in which silica is modified with nonionic emulsifier (PA+K25 NE) the particle size distribution is also bimodal [Figure 1(b)] but with less pronounced bimodal character in relation to the systems with unmodified silica. In $\mathrm{PA}+$ silica systems in which silica surface is modified with cationic initiator AIBA (PA+K25 AIBA) particle size distributions are narrow and monomodal [Figure 1(c)].

Additional perspective of the particle size distribution is shown on Figure 2, characteristic values of the particle size distribution, Sauter mean diameter has been plotted as a function of silica mass fraction and surface modification.

$\mathrm{PA}+$ silica systems with unmodified silica and silica modified with nonionic emulsifier and cationic initiator AIBA have micrometer particle sizes in range 10-66 $\mu \mathrm{m}$ depending upon

Figure 2 Sauter mean diameter; the effect of filler mass ratio

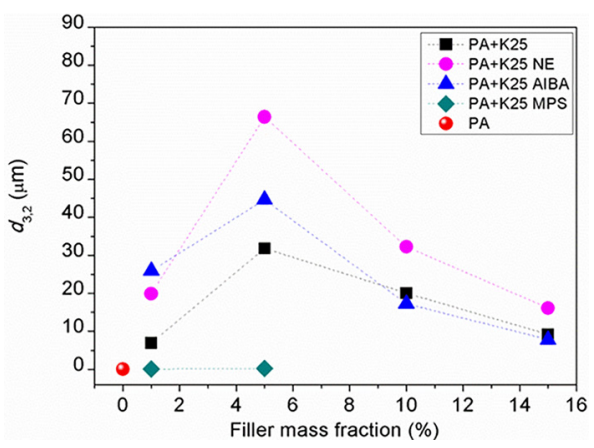

Figure 1 Graphic view of experimental PSDs for PA systems with (a) unmodified, (b) nonionic emulsifier, (c) cationic initiator and (d) silane modified silica filler

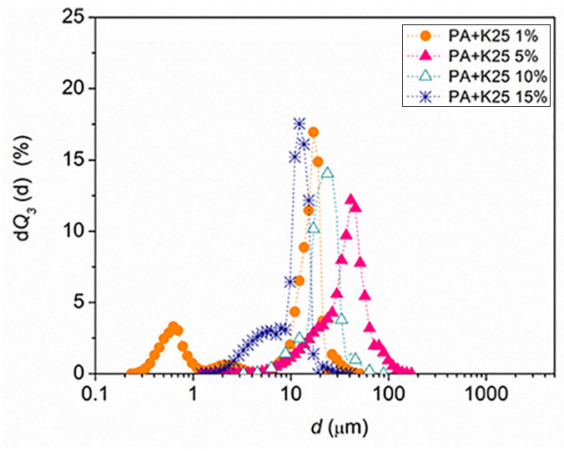

(a)

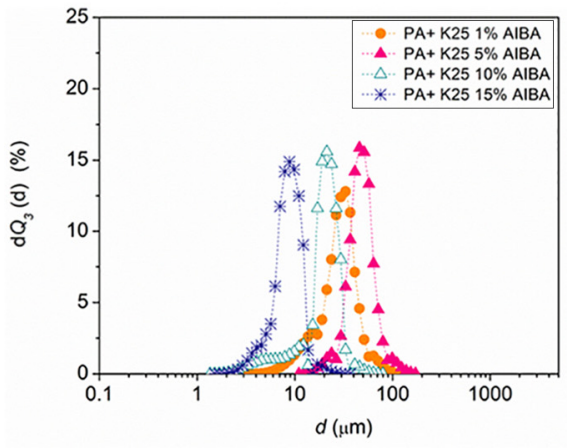

(c)

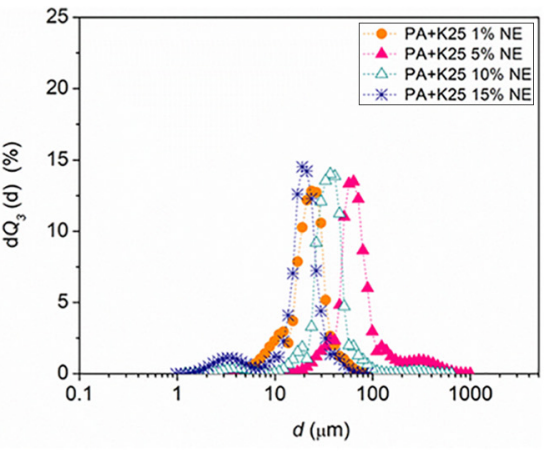

(b)

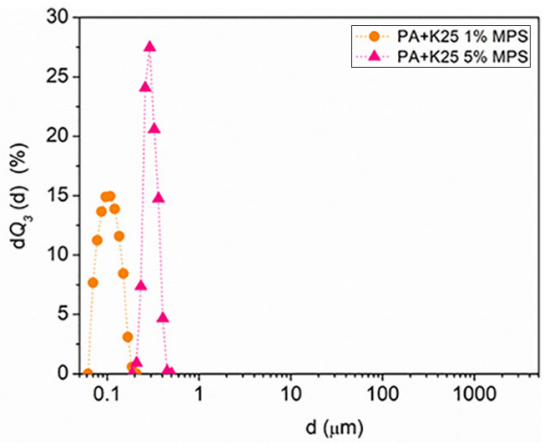

(d) 
filler concentration. In the literature (Luna-Xavier et al., 2001; Qi et al., 2006; Dashtizadeh et al., 2011; Wen et al., 2008) PA+silica systems with silica modified with nonionic emulsifiers and AIBA have particles in nanometer size. However, as it was mentioned before the monomer/water weight ratio in these systems was from $1 / 100$ to $19 / 100$ while in the systems prepared in this work, monomer/water ratio was significantly higher; 70/100. In the case of high monomer/water ratio there will be a higher tendency of agglomeration. Consequently, larger latex particles are formed and observed.

From previous mentioned investigations of $\mathrm{PA}+$ silica systems (Luna-Xavier et al., 2001; Qi et al., 2006; Dashtizadeh et al., 2011; Wen et al., 2008), it is clear that there is a significant difference in the concentration of silica particles (20 to $50 \%$ ) beside monomer water/ratio. However, in this work the concentration of silica is $0-15 \%$ (based on the monomer mass). According to the literature (Bourgeat-Lami et al., 2006); when the number i.e. concentration of silica particles in the system is low, the size of the resulting organic/inorganic particles highly depends on the concentration of the anionic emulsifier. However, with increasing the number of silica particles in the system, the number of resulting organic/ inorganic particles increases and the size of the particles decreases. This indicates that the concentration of filler particles in the system determine the size of the resulting latex particles. In all systems (except those where silica is modified with silane), there is a decrease of the particle sizes with increase of the silica concentration (10 and 15\%). To investigate whether it is possible to reduce the latex particle size with a significant increase of the silica concentration, PA systems with $50 \%$ of unmodified and silica modified with nonionic emulsifier were prepared.

From the Figure 3(a), it is obvious that the particle sizes of $\mathrm{PA}+$ silica emulsion with $50 \%$ of silica are in nanometer size range with average size of about $520 \mathrm{~nm}$ for a system with unmodified silica and $650 \mathrm{~nm}$ for the system in which silica is modified with nonionic emulsifier. From the obtained results, it can be concluded that increasing the concentration of silica particles leads to a significant decreasing of the PA+silica emulsion particle size from micrometer to nanometer dimensions.

Micrometer particle sizes for PA+silica systems where silica is modified with nonionic emulsifier and cationic initiator might be due to the use of nonionic emulsifier as well. The nonionic emulsifier can cause the agglomeration of silica particles due to the "bridging flocculation," i.e. bridging of particles by surface micelles (Giordano-Palmino et al., 1994). As the coverage of the filler surface with nonionic emulsifier exceeds more than $10 \%$, most of the adsorbed surfactant molecules are in a form of micelles which are similar in size. The flocs could then be imagined as large spheres (silica) bound by smaller spheres (surface micelles). Therefore, initial particles are larger and as a consequence, larger nanocomposite particles will be formed.

To determine whether the growth of the particles occurs during or at the end of the polymerization process, synthesis of PA + silica systems with $15 \%$ of unmodified silica and silica modified with nonionic emulsifier, with only a part $(25 \%)$ of the total amount of premulsion was carried out. From the results in Figure 3(b), it is evident that nanocomposite particles are significantly larger compared to particles of a neat polyacrylate emulsion $(<80 \mathrm{~nm})$ and added silica nanofiller $(25 \mathrm{~nm})$. Therefore, it can be concluded that the size of the composite particles was defined in the earlier stage of polymerization and it is not a consequence of an agglomeration on the end of the polymerization process. In the system in which silica is modified with nonionic emulsifier particle sizes are 10 times larger than the particles in a system with unmodified silica surface [Figure 3(b)]. This is confirmation that the nonionic emulsifier can be a cause's agglomeration of the particles.

Significantly different, systems in which silica is modified with silane (PA+K25 MPS) own nanometer sized particles with narrow and monomodal particle size distributions [Figure 1(d)]. Possible reason of nanometer particle sizes is the formation of silica particles due to the hydrolysis and condensation of silane. Therefore, the number of centers for nucleation is increased and smaller nanometer particles occur. Furthermore, in the synthesis of a system in which silica surface is modified with silane nonionic emulsifier was not used. System with higher amount (5\%) of silica filler modified with MPS has higher particle sizes [Figure 1(d)] than system with $1 \%$ of the filler. At higher silica concentration higher amount of silane is needed to achieve the efficient modification of silica surface. Silane molecules will undergo hydrolysis and condensation in the presence of water forming siloxane polymer network, which can also interact mutually and therefore will form larger composite particles.

Figure 3 Graphic view of experimental PSDs for PA system with (a) $50 \%$ of silica and (b) $15 \%$ of silica but with $1 / 4$ premulsion addition

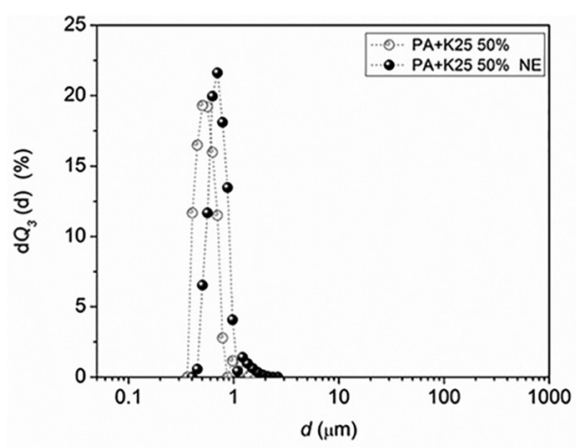

(a)

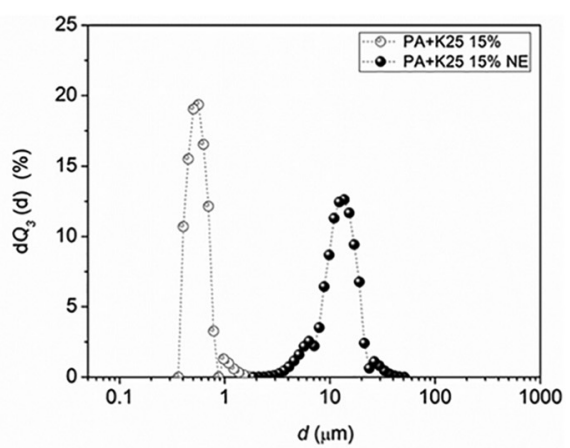

(b) 


\subsection{Rheology}

Significant effects on latex viscosity have particle size distribution, interactions between the particles and the concentration of solid particles (Litchfield and Baird, 2006). Rheological diagrams of PA and PA+silica emulsions are shown on Figure 4. Rheological behavior of PA+ silica systems with modified silica is very similar therefore only the diagram for PA+ silica systems in which silica is modified with AIBA is presented in Figure 4(b). With increasing the silica concentration, emulsion viscosity is increasing. The only difference is visible in system with $10 \%$ of silica modified with nonionic emulsifier which has a slightly lower viscosity compared to the system with the $5 \%$ silica. This could be a consequence of bimodal particle size distribution. At bimodal distribution, there are small and big particles and viscosity depends upon the ratio and the diameter of large and small particles (Schneider et al., 2002). Systems with modified silica have higher viscosity in relation to the systems with unmodified silica in concentration range up to $10 \%$ (Fig 4). Varying the surface modification and concentration of silica very broad range of PA emulsion viscosity can be obtained.

$\mathrm{PA}+$ silica emulsions with smaller amounts of silica show Newtonian behavior and system with higher amounts of silica show non-Newtonian; pseudoplastic behavior regardless silica surface modification. Systems with $15 \%$ of silica filler showed also rheopectic behavior which is the most pronounced in systems where silica is modified with nonionic emulsifier. The phenomenon of rheopexy is very rare, and it has been observed in very concentrated $\mathrm{W} / \mathrm{O}$ emulsion and in emulsions
Figure 5 Experimental and calculated viscosity with Ostwald-de Waele model of PA systems with silica modified with cationic initiator AIBA

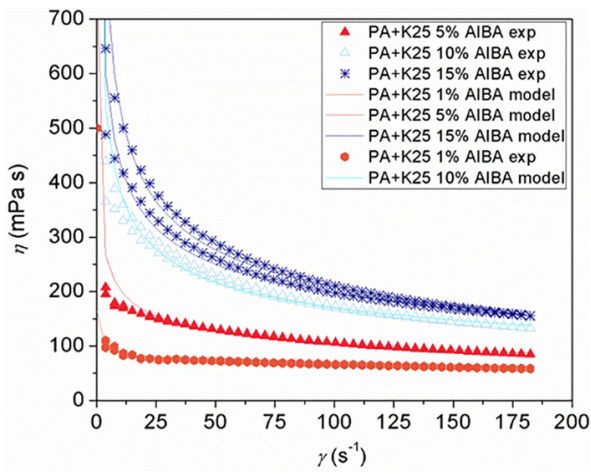

(Mollet and Grubenmann, 2001) where the amount of the dispersed phase is greater than $30 \%$.

Experimental results of rheological behavior were analyzed using models describing Newtonian behavior [equation (1)] and non-Newtonian behavior through Ostwald-de Waele model [equation (2)]. The results of apparent viscosity are given in Table 2.

For emulsions with rheopectic behavior two models for apparent viscosity are shown, one model for increasing the shear rate from 0 to $182 \mathrm{~s}^{-1}$ and the other for decreasing the shear rate from 182 to $0 \mathrm{~s}^{-1}$.

For all PA+silica emulsions prepared in this work, the experimental values are in good agreement with the calculated

Figure 4 Rheological diagrams for PA systems with (a) unmodified and with (b) cationic initiator modified silica

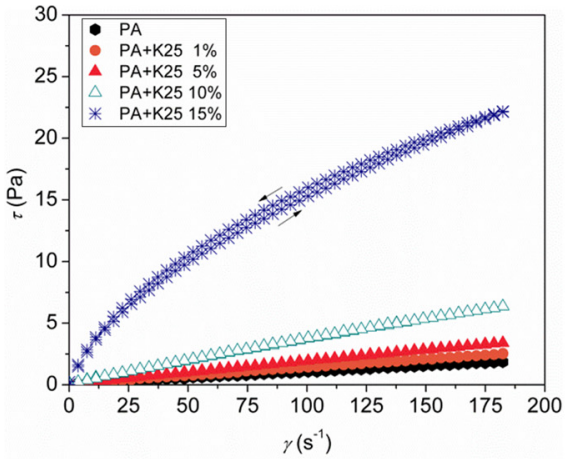

(a)

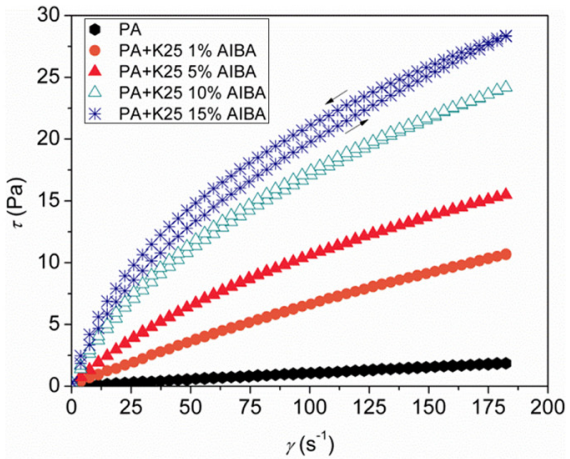

(b)

Table 2 Viscosity of PA and PA + silica emulsions

\begin{tabular}{|c|c|c|c|c|}
\hline \multicolumn{5}{|c|}{$\eta(\mathrm{mPa} s)$} \\
\hline System & without modification & NE & AIBA & MPS \\
\hline PA & 10.5 & - & - & - \\
\hline $\mathrm{PA}+\mathrm{K} 251 \%$ & 14.2 & 32.8 & $120 \cdot \gamma^{-0.132}$ & $137 \cdot \gamma^{-0.152}$ \\
\hline$P A+K 255 \%$ & 19.2 & $158 \cdot \gamma^{-0.154}$ & $393 \cdot \gamma^{-0.288}$ & $467 \cdot \gamma^{-0.308}$ \\
\hline$P A+K 2510 \%$ & 36.3 & $114 \cdot \gamma^{-0.129}$ & $862 \cdot \gamma^{-0.352}$ & - \\
\hline $\mathrm{PA}+\mathrm{K} 2515 \%$ & $1211 \cdot \gamma^{-0.417}$ & $\begin{array}{l}361 \cdot \gamma^{-0.233} \\
1473 \cdot \gamma^{-0.512}\end{array}$ & 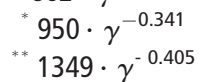 & - \\
\hline
\end{tabular}


Figure 6 SEM micrographs of PA+silica systems, magnification $20 \mathrm{kx}$

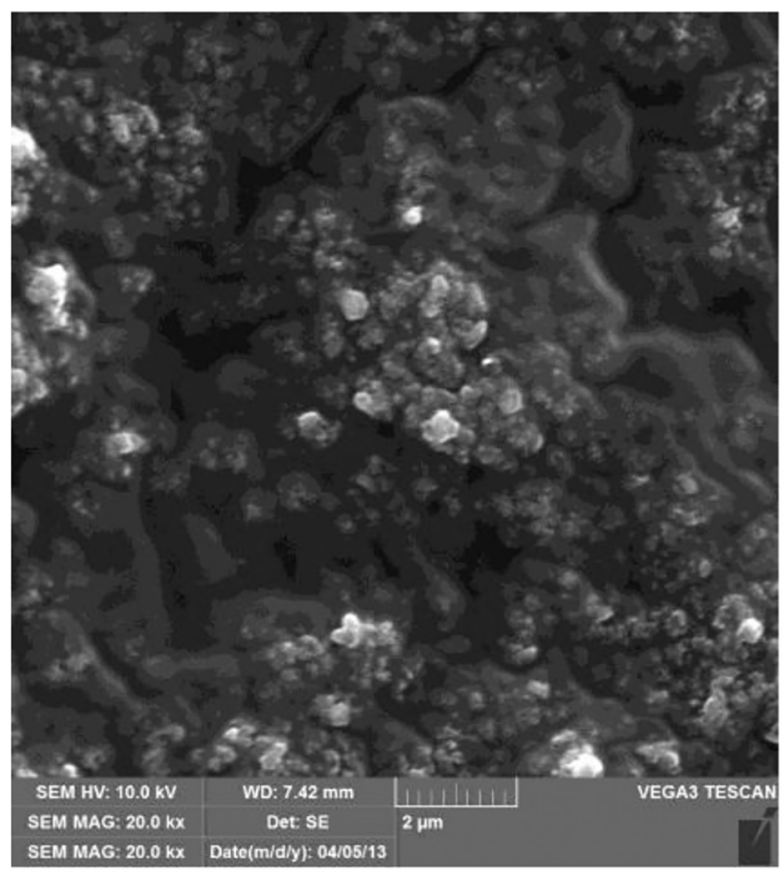

(a)

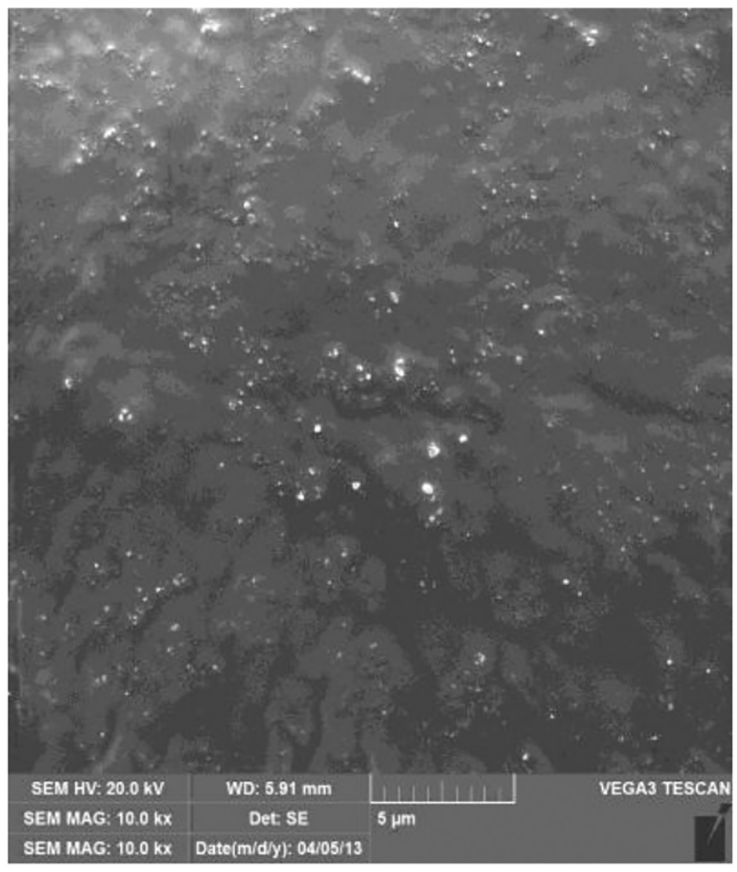

(c)

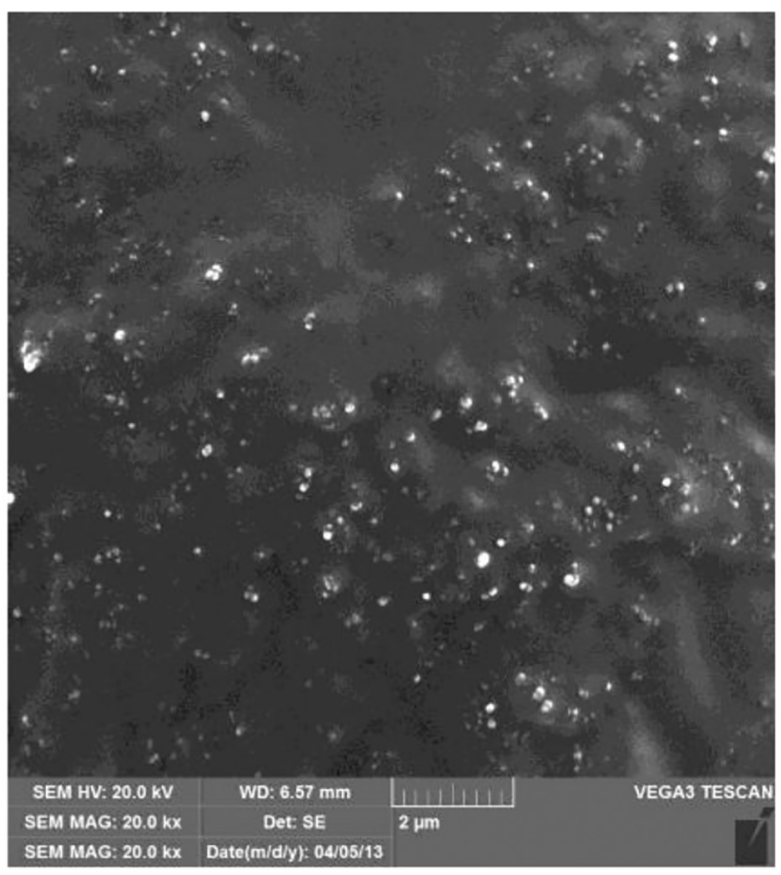

(b)

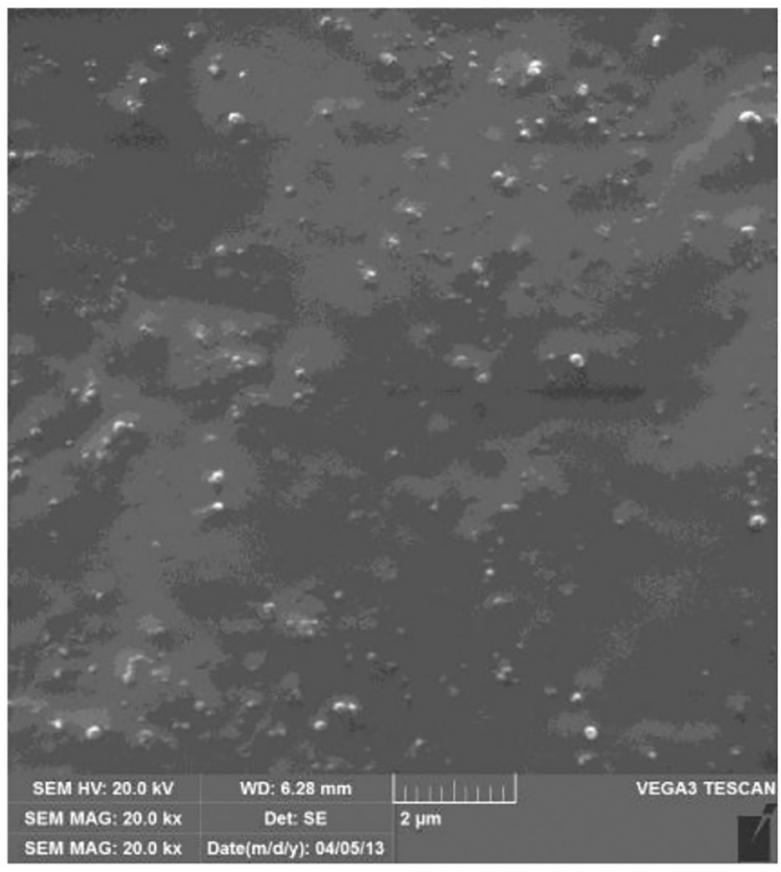

(d)

Notes: (a) PA1K25 5\%; (b) PA1K25 5\% NE; (c) PA1K25 5\% AIBA; (d) PA1K25 5\% MPS

values of viscosity according to the Ostwald-de Waele model [equation (2); Figure 5]. Excellent matching is obtained at shear rates above $25 \mathrm{~s}^{-1}$. Therefore, it can be concluded that the rheological behavior of PA+silica emulsions can be described using Newtonian or Ostwald-de Waele model.

\subsection{Morphology}

The morphology of polymer composite systems includes the size, shape and phase distribution within the polymer. The study of morphology of polymer composite is very important for the explanation of material properties. From the SEM 
micrographs, it is possible to see the dispersion of filler in the polymer matrix and estimate the particle size. Figure 6 shows SEM micrographs of the PA+silica systems with $5 \%$ of unmodified and differently modified silica filler. SEM micrographs show that in the system with unmodified silica significant filler agglomeration occurs and the silica filler is not evenly distributed in the film. In the systems with modified silica filler, the filler particles are smaller and the filler is uniformly distributed through the polymer matrix. The obtained results are in accordance with expectations, as it is assumed that in systems in which the filler surface is modified, polymerization occurs near the surface of the silica particles causing better dispersion in the polymer matrix.

\subsection{Thermal properties}

Glass transition temperature, $T_{\mathrm{g}}$, obtained from the DSC curves are shown in Table 3. Results indicate that concentration and surface modification of silica nanofiller have no significant effect on the $T_{\mathrm{g}}$ of polyacrylate. According to the Lipatov equation (Lipatov, 1995), surface modification of the filler changes interactions at the matrix/filler interface and effect the flexibility of the polymer chains. Therefore, it can be expected that the addition of the filler will change glass transition temperature of polymer matrix. Obviously, PA chains in these systems have high flexibility which is additionally increased by added anionic emulsifier. Therefore, interactions at the matrix/filler interface due to the modification of silica surface have no effect on the $T_{\mathrm{g}} . T_{\mathrm{g}}$ of the PA+silica systems prepared in this study are for $\sim 4^{\circ} \mathrm{C}$ lower than the $T_{\mathrm{g}}$ of $\mathrm{PA}+$ silica systems prepared in our previous work (Buhin et al., 2013). It is presumed that the reason of a lower $T_{\mathrm{g}}$ is higher amount of anionic emulsifier which behaves as a plasticizer.

To determine the thermal stability of PA and PA+silica systems, thermogravimetric analysis (TGA) was used. It is known from the literature that the addition of filler can increase thermal stability of polymers (Wang et al., 2003; Liu et al., 2004; Park and Cho, 2003). Increase in thermal stability of the polymer matrix with the addition of nanofiller may be due to the improved barrier (oxygen) properties of the composites. If oxygen cannot penetrate, then it cannot cause oxidative degradation of the polymer resin. In addition, the inorganic phase can act as a radical sink to prevent polymer chains from decomposing (Ajayan et al., 2003). TG curves for PA+silica system in which silica is modified with cationic initiator (AIBA) are shown in Figure 7. The results show that the decomposition of PA and PA+ silica systems take place in a temperature range from 220 to $400^{\circ} \mathrm{C}$ in a one-step degradation process. After $10 \%$ of sample mass loss decomposition temperatures

Table 3 Glass transition temperature $\left(T_{g}\right)$ of PA and PA + silica films

\begin{tabular}{lcccc}
\hline System & $\begin{array}{c}T_{\mathrm{g}}\left({ }^{\circ} \mathrm{C}\right) \\
\text { without modification }\end{array}$ & NE & AIBA & MPS \\
\hline PA & 6.0 & - & - & - \\
PA+K25 1\% & 5.3 & 5.9 & 5.4 & 5.4 \\
PA+K25 5\% & 5.9 & 6.0 & 7.9 & 5.3 \\
PA+K25 10\% & 6.3 & 6.0 & 5.4 & - \\
PA+K25 15\% & 7.4 & 8.1 & 5.9 & - \\
\hline
\end{tabular}

Figure 7 TG curves of PA systems with silica modified with cationic initiator

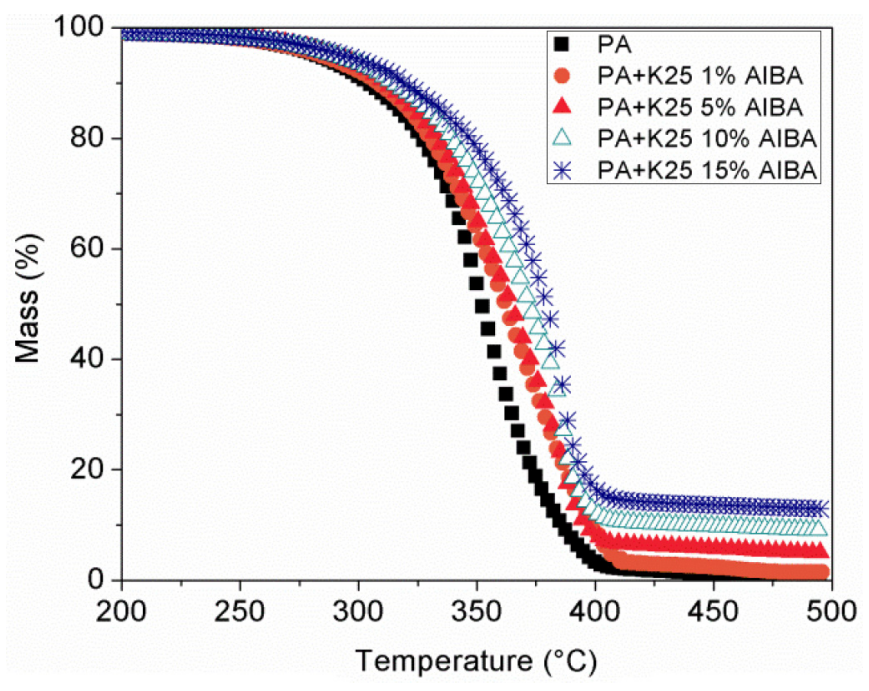

continuously increases with increasing the silica concentration. The same behavior showed all prepared PA+ silica systems.

Decomposition temperatures $T_{5}$ and $T_{50}$ (temperature at 5 and $50 \%$ of the sample mass loss) as a function of the silica mass fraction are shown in Figure 8. From Figure 8(a), it is clear that the addition of the silica in PA matrix decrease $T_{5}$ except in the systems where silica surface is modified with AIBA (PA+K25 AIBA); where $T_{5}$ is increased in the whole concentration range of added silica. Significant increase of $T_{5}$ for $11^{\circ} \mathrm{C}$ is observed for system with $15 \%$ of silica modified with AIBA. PA+ silica systems have higher values of $T_{50}$ than neat PA matrix [Figure 8(b)], in the whole concentration range regardless silica surface modification. The results imply that in the later stage of degradation the addition of silica filler improves thermal properties of neat PA matrix. Systems in which silica surface is modified with cationic initiator, AIBA have shown the highest improvement of thermal stability.

\subsection{Mechanical properties}

The mechanical properties of the material can be alter by adding fillers, additive or by surface treatment of the basic material (Basta et al., 2014; Jeon and Baek, 2010; Basta, 2003). However, due to the poor compatibility between the polymer matrices and the inorganic particles mechanical properties could be disturbed. Filler surface modification is expected to improve interactions on the filler/matrix interface, which has a strong effect on the mechanism of failure of composite material and therefore on mechanical properties.

Addition of silica in PA matrix (Figure 9) mainly increased tensile strength $\left(\sigma_{\mathrm{R}}\right)$, which indicates reinforcing effect of silica. In systems with unmodified silica filler, modified with nonionic emulsifier and cationic initiator the highest values of tensile strength have systems with $10 \%$ of silica. Our previous results (Buhin et al., 2013) also showed that the highest value of tensile strength has system with $10 \%$ of unmodified silica filler. From the given results, it can be presumed that $10 \%$ of silica filler in PA matrix is optimal content to achieve highest values of tensile strength. 
Figure 8 Temperatures at which sample lost $5 \%\left(T_{5}\right)$ and $50 \%\left(T_{50}\right)$ of mass

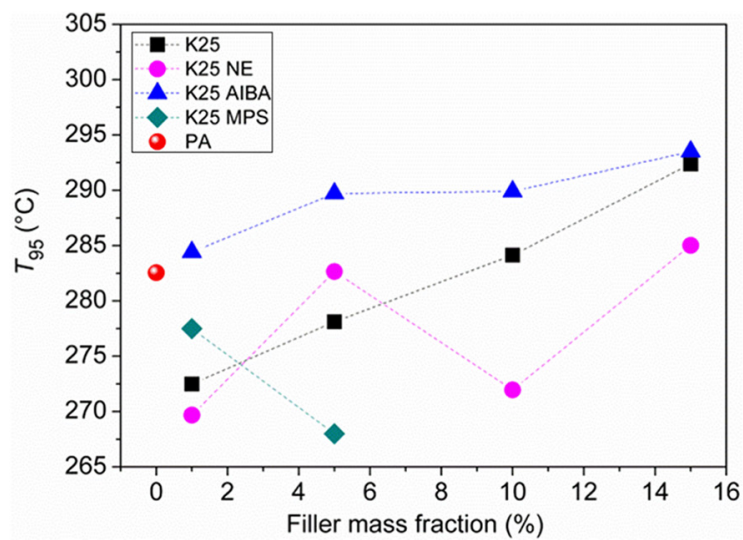

(a)

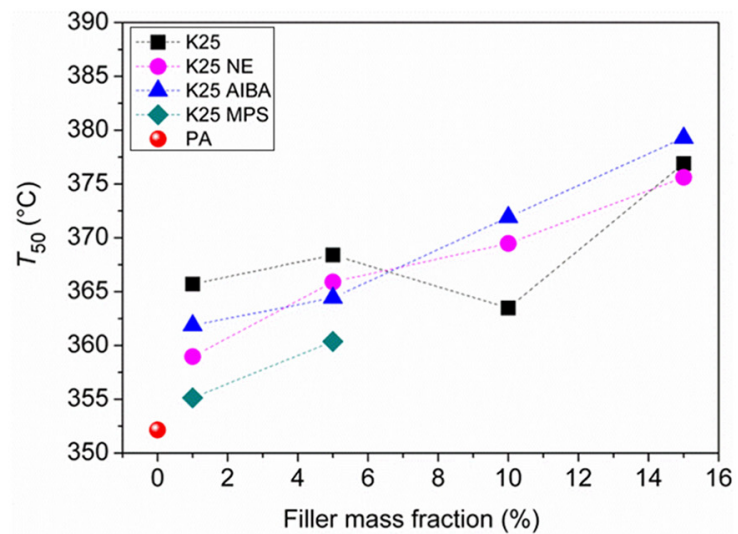

(b)

Figure 9 Stress/strain curves for PA systems with (a) unmodified, (b) nonionic emulsifier, (c) cationic initiator and (d) silane modified silica filler

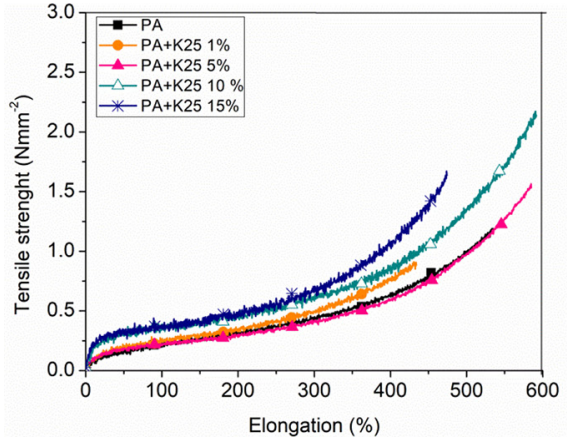

(a)

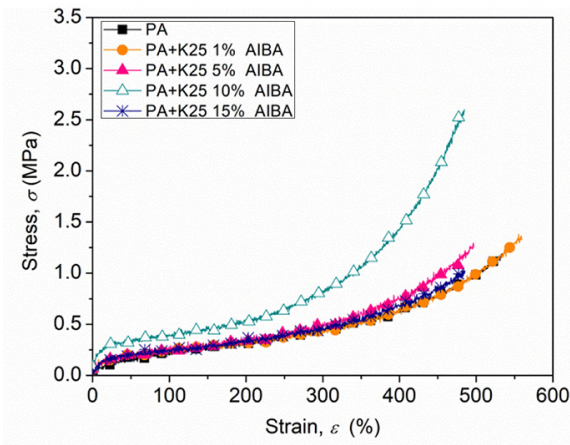

(c)

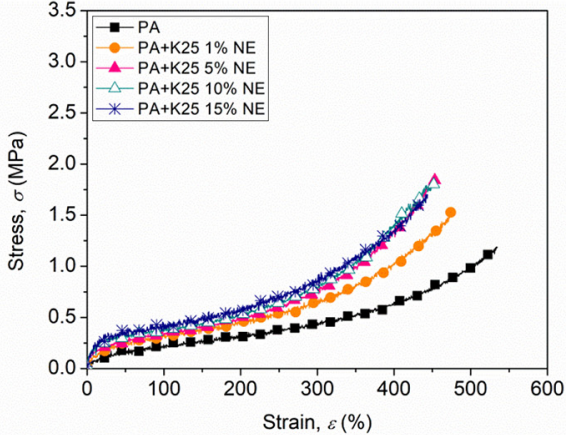

(b)

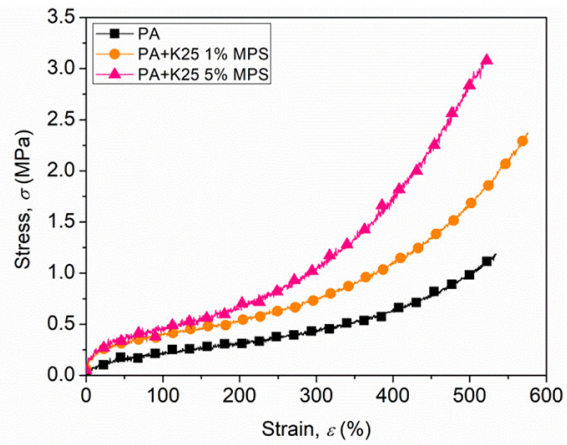

(d)

decreased elongation at break 10 times in relation to neat matrix (Kickelbick, 2007). Also, in the composite system (Leskovac et al., 2004) PVAc $+15 \% \mathrm{CaCO}_{3}$, elongation was decreased from 310 to $150 \%$. In PA+ silica systems prepared in this work elongation at break was not significantly reduced with filler addition, even in some systems elongation was higher than for neat PA matrix $(\varepsilon=534 \%)$.

\section{Conclusions}

PA systems with unmodified silica, silica modified with nonionic emulsifier and cationic initiator, in concentration range $0-15 \%$, have micrometer particle sizes. In the earlier 
stages of polymerization particles grow and modification of silica with nonionic emulsifier additionally increases particle growth due to the "bridging flocculation" of the nonionic emulsifier. In the systems with silica modified with nonionic emulsifier with increasing the concentration of silica filler, up to $50 \%$, nanometer particle sizes are obtained. Surface modification and concentration of silica filler affect particle size distribution of PA emulsion. Systems in which silica is modified with silane have nanometer particle sizes with monomodal and narrow particle size distribution.

Surface modification of the filler affects the nanocomposite morphology; the filler particles are smaller and the filler is uniformly distributed through the polymer matrix.

Addition of modified silica has significant influence on rheological properties of PA emulsions. Systems in which silica is modified with nonionic emulsifier, cationic initiator and silane have significantly higher viscosities than neat PA emulsion. In emulsions with small concentration of silica filler, Newtonian behavior, and in emulsions with higher filler concentration, pseudoplastic and rheopectic behavior are observed. Apparent viscosity of PA+silica emulsions that showed pseudoplastic behavior is described with Ostwald-de Waele model.

Glass transition temperatures of PA films were unchanged regardless filler concentration and surface modification. TG analysis showed that concentration and surface modification of silica have effect on PA thermal stability. The best thermal stability showed systems in which silica surface is modified with cationic initiator, AIBA.

For PA systems with unmodified silica filler, silica filler modified with nonionic emulsifier and cationic initiator AIBA, $10 \%$ is the optimal concentration at which the highest value of the tensile strength is achieved. The highest values of tensile strength are observed in systems where silica surface is modified with silane, MPS, as a consequence of chemical bonds between silica and polymer matrix. Silica caused slightly reduction of PA elongation at break for some PA+silica systems depending upon silica concentration and surface modification. The most successful filler surface modification is with silane, due to the interaction between the filler and polymer as a consequence of filler modification with silane.

Future studies will be focused also on filler surface modification and preparation of PA+silica systems with different silica filler particle sizes.

\section{References}

Ajayan, P.M., Schadler, L.S. and Braun, P.V. (2003), Nanocomposites Science and Technology, Wiley-VCH, Wienheim.

Anderson, C.D. and Daniels, E.S. (2003), "Emulsion polymerization and latex applications", Rapra Review Reports, Vol. 14 No. 4.

Basta, A.H. (2003), "The role of chitosan in improving the ageing resistance of rosin sized paper", Restaurator, Vol. 24, pp. 106-117.

Basta, A.H., El-Saieda, H. and Lofty, V.F. (2014), "Performance assessment of deashed and dewaxed rice straw on improving the quality of RS-based composites", RSC Advances, Vol. 4 No. 42, pp. 21794-21801.
Bourgeat-Lami, E., Insulaire, M., Reculusa, S., Perro, A., Ravaine, S. and Duguet, E. (2006), "Nucleation of polystyrene latex particles in the presence of $\gamma$-methacryloxypropyltrimethoxysilane: functionalized silica particles", fournal of Nanoscience and Nanotechnology, Vol. 6 No. 2, pp. 432-444.

Buhin, Z., Lučić Blagojević, S. and Leskovac, M. (2013), "In situ emulsion polymerization and characterization of poly (butyl acrylate-co-methyl methacrylate)/silica nanosystems", Polymer Engineering [E] Science, Vol. 53 No. 11, pp. 2292-2298.

Dashtizadeh, A., Abdouss, M., Mahdavi, H. and Khorassani, M. (2011), "Acrylic coatings exhibiting improved hardness, solvent resistance and glossiness by using silica nanocomposites", Applied Surface Science, Vol. 257 No. 6, pp. 2118-2125.

Giordano-Palmino, F., Denoyel, R. and Rouqueroul, J. (1994), "Interfacial aggregation of nonionic surfactant: effect on the stability of silica suspension", Fournal of Colloid and Interface Science, Vol. 165 No. 1, pp. 82-90.

Hashemi-Nasaba, R. and Mirabedini, S.M. (2013), "Effect of silica nanoparticles surface treatment on in situ polymerization of styrene-butyl acrylate latex", Progress in Organic Coatings, Vol. 76 Nos 7/8, pp. 1016-1023.

Jeon, I.Y. and Baek, J.B. (2010), "Nanocomposites derived from polymers and inorganic nanoparticles", Materials, Vol. 3 No. 6, pp. 654-3674.

Kazakova, M.A., Semikolenova, N.V., Korovin, E.Y., Moseenkov, S.I., Andreev, A.S., Kachalov, A.S., Kuznetsov, V.L., Suslyaev, V.I., Mats'ko, M.A. and Zakharov, V.A. (2018), "In situ polymerization technique for obtaining composite materials based on polyethylene, multi-walled carbon nanotubes and cobalt nanoparticles", Russian fournal of Applied Chemistry, Vol. 91 No. 1, pp. 127-135.

Kickelbick, G. (2007), "Hybrid materials", Synthesis, Characterization and Applications, Wiley-VCH Verlang GmbH [\&] Co. KgaA, Weinheim, p. 77.

Laoutid, F., Bonnaud, L., Alexandre, M., Lopez-Cuesta, J.-M. and Dubois, P. (2009), "New prospects in flame retardant polymer materials: from fundamentals to nanocomposites", Materials Science and Engineering: R: Reports, Vol. 63 No. 3, pp. 100-125.

Leskovac, M., Kovačević, V., Lučić Blagojević, S., Vrsaljko, D. and Volovšek, V. (2004), "Pre-treatment of $\mathrm{CaCO}_{3}$ nanofiller by irradiation in the presence of vinyl monomers for the preparation of poly(vinyl acetate) composites", ePolymers, Vol. 4 No. 1, pp. 1618-7229.

Li, Y., Xu, T., Tu, Z., Dai, W., Xue, Y., Tang, C., Gao, W., Mao, C., Lei, B. and Lin, C. (2020), "Bioactive antibacterial silica-based nanocomposites hydrogel scaffolds with high angiogenesis for promoting diabetic wound healing and skin repair", Theranostics, Vol. 10 No. 11, pp. 4929-4943.

Lipatov, Y.S. (1995), Polymer Reinforcement, ChemTec, Ontario.

Litchfield, D.W. and Baird, D.G. (2006), "The rheology of high aspect ratio nanoparticle filled liquids", Rheology Reviews, pp. 1-60.

Liu, Y.L., Wei, W.L., Hsu, K.Y. and Ho, W.H. (2004), "Preparation and thermal properties of epoxy-silica nanocomposites from nanoscale colloidal silica", Polymer, Vol. 44No No. 18, pp. 5159-5167. 
Liua, Y.-L., Hsu, C.-Y., Wie, W.-L. and Jeng, R.-J. (2003), "Preparation and thermal properties of epoxy-silica nanocomposites from nanoscale colloidal silica", Polymer, Vol. 44 No. 18, pp. 5159-5167.

Lotfy, V.F., Fathy, N.A. and Basta, A.H. (2018), "Novel approach for synthesizing different shapes of carbon nanotubes from rice straw residue", fournal of Environmental Chemical Engineering, Vol. 6 No. 5, pp. 6263-6274.

Luna-Xavier, J.-L., Bourgeat-Lami, E. and Guyot, A. (2001), "The role of initiation in the synthesis of silica/poly(methyl methacrylate) nanocomposite latex particles through emulsion polymerization", Colloid E Polymer Science, Vol. 279 No. 10, pp. 947-958.

Ma, M., Li, H., Xiong, Y. and Dong, F. (2021), “,,rational design, synthesis, and application of silica/graphene-based nanocomposite: a review", Materials and Design, Vol. 198.

Mollet, H. and Grubenmann, A. (2001), Formulation Technology, WILEY-VCH, Weinheim.

Motaung, T.E., Mochane, M.J., Linganiso, Z.L. and Mashigo, A.P. (2017), "In situ polymerization of Nylon-Cellulose nano composite", Polymer Science, Vol. 3 Nos 1, pp. 1-8.

Najam, M., Hussain, M., Ali, Z., Maafa, I.M., Akhter, P., Majeed, K., Ahmed, A. and Shehzad, N. (2020), "Influence of silica materials on synthesis of elastomer nanocomposites: a review", Fournal of ElasticsEPlastics, Vol. 52 No. 8, pp. 747-771.

Park, S.J. and Cho, K.-S. (2003), "Filler-elastomer interactions: influence of silane coupling agent on crosslink density and thermal stability of silica/rubber composites",
Fournal of Colloid and Interface Science, Vol. 267 No. 1, pp. 86-91.

Platikanov, D. and Exerowa, D. (2009), Highlights in Colloid Science, Wiley-Verlang GmbH, Weinheim.

Qi, D.-M., Bao, Y.-Z., Huang, Z.-M. and Weng, Z.-X. (2006), "Synthesis and characterization of poly(butyl acrylate)/silica and poly(butyl acrylate)/silica/poly(methyl methacrylate) composite particles", Fournal of Applied Polymer Science, Vol. 99 No. 6, pp. 3425-3432.

Rong, M.Z., Zhang, M.Q. and Ruan, W.H. (2006), "Surface modification of nanoscale fillers for improving properties of polymer nanocomposites: a review", Materials Science and Technology, Vol. 22 No. 7, pp. 787-796.

Schneider, M., Claverie, J., Graillat, C. and Mckenna, T.F. (2002), "High solids content emulsions. I. A study of the influence of the particle size distribution and polymer concentration on viscosity", fournal of Applied Polymer Science, Vol. 84 No. 10, pp. 1878-1896.

Wang, Y.T., Chang, T.C., Hong, Y.S. and Chen, H.B. (2003), "Effect of the interfacial structure on the thermal stability of poly(methyl methacrylate)-silica hybrids", Thermochimica Acta, Vol. 397 Nos 1/2, pp. 219-226.

Wen, X., Li, M., Pi, P., Chen, J. and Yang, Z. (2008), "Study of the physicochemical properties of silica powder and the stability of organic-inorganic hybrid emulsion in the presence of ethanol", Colloids and Surfaces A: Physicochemical and Engineering Aspects, Vol. 327 Nos 1/3, pp. 103-110.

\section{Corresponding author}

Zrinka Buhin Šturlić can be contacted at: zbuhin@flkit.hr 